\title{
Women's empowerment after the rapid expansion of higher education in Turkey: Developments and paradoxes of gender equality in the labour market
}

Turkey has experienced an expansion in higher education over the last 15 years as fuelled by the cancellation of tuition fees, the establishment of at least one public university in each city, an increase in the number of foundation universities, and the abolition of the headscarf ban. Within this period, women overtook men in terms of higher education attainment. In this paper, we study whether this development went alongside improved gender equality in the labour force. We analyse household labour force survey data for the years 2005, 2008, 2011 and 2017 to track the changes in core SDG5-indicators for gender equality: labour force participation, gender segregation in employment, and the gender pay gap. Overall, we find that women with higher education still enter the labour force much more often than women without higher education. While both occupational gender segregation and the gender wage gap persist among graduates, they remain at a comparatively low level by international comparison. Our analysis shows that higher education contributed to a large degree to the development towards a somewhat more equal labour market in Turkey among the most recent cohort despite the nuanced and entrenched gender inequalities that otherwise are resilient to change.

\section{Keywords}

Gender inequality in the labour market; gender pay gap; Turkey; higher education expansion; occupational gender segregation; 


\section{Introduction}

\subsection{Motivation}

Higher education has been greatly expanded over the last 15 years in Turkey. The number of universities has more than doubled and enrolment rates among 18-22-year-olds increased rapidly from $14.64 \%$ in 2002 to $45.64 \%$ in 2018 (MoNE 2018). As in many other low- and middle-income countries (LMICs), this expansion came with a strongly increasing rate of women in higher education (Flashman 2013) leading to gender parity or even a female dominance on campus (Chang 2018). However, numerical gender equality alone offers a limited understanding of the overall change in gender relations in a society and does not reveal how expansion changed women's opportunities in life (Author A, 2017). To exemplify, it is unclear to what extent the increase in participation in tertiary education went along with greater economic independence via labour market participation in Turkey. Although higher education can play a significant role in closing the gender gap in the labour market, some also argue that the opportunities provided by higher education may not necessarily bring material betterment (Marginson 2016; Ahmed and HyndmanRizk 2018), particularly in highly patriarchal or hierarchical contexts. Therefore, we ask which of the two scenarios is a better description of the recent expansion in the Turkish higher education sector: a strengthening of the equalization of women through an improved standing in the labour market, or an equalization that is limited to the fact that women nominally get the same educational degrees, but cannot subsequently turn this into economic independence.

In many ways, a broad equalization within the labour market via higher education expansion in Turkey would be against the odds. Scholars have long argued that the low participation rate cannot purely be explained by education, emphasizing the social norms that expect men to be bread-winner and women to take care of the family and the children (Göksel 2013; Ilkkaracan 2012). Employment rates amongst women are indeed low by international standards, where the gender employment gap is the highest among the 
OECD countries ${ }^{1}$. If social norms cause this strong division of labour, the expansion of higher education might do little to nothing to bring more women into employment, especially considering that the expansion into the eastern regions and the lifting of the headscarf probably brought more women with traditional values into higher education. However, based on more economic arguments about employability, several scholars expressed the expectation that higher education could change these figures towards more female employment (Atasoy 2017; Dildar 2015). This hypothesis seems more plausible when considering the situation of highly educated women prior to the reform. While the general participation rate of women is low and gendered norms of the division of work are known to be strong, women with higher education have, in fact, long been actively participating in the labour market in Turkey with, for example, 71.3 per cent employment in one of the latest reports from the country's official statistics (TUIK 2018). The overall low level of labour market participation is driven by women with less education, especially from the least developed as well as the most conservative/traditional parts of the country, who have, effectively, been excluded from the labour market (Göksel 2013; Gündüz-Hoşgör and Smits 2008).

In this article, we address the question how the rapid expansion of higher education in Turkey affected the gender gaps in labour force participation and pay as well as occupational segregation. Our analyses are based on the Turkish Household Labour Force Survey. Although our results show that higher education remains a key entry ticket into the labour market, there is also a small increase in the number of women with a qualification in higher education who withdraw from employment to accommodate their unpaid household responsibilities. At the same time, occupational gender segregation and the gender wage gap remain stable at a rather low level in comparison to other countries.

\subsection{The expansion of higher education in Turkey}

\footnotetext{
${ }^{1}$ In 2017 , the labour force participation rate for working age women in Turkey was $29.3 \%$ in 2017 whereas men's participation was 72.7 (OECD, 2018).
} 
Over the last 15 years, the higher education system in Turkey changed from that of a selective elitist institution to mass higher education. In parallel with the rapid increase in enrolment, the number of public universities increased from 53 in 2005 to 129 in 2019. A similar development has been seen in the establishment of foundation (Vak1f) universities ${ }^{2}$, leading to a total of 202 universities as of 2019. Besides the increase in the relative frequency of a cohort enrolling, the Turkish higher education sector also grew to cater the demands of an ever-growing youth population (Mizikaci 2003) and a rapidly growing economy after 2002 (Özoğlu et al. 2016). Another aim of the expansion was the promotion of social equality, and the creation of new capacities was accompanied by the abolition of tuition fees at public universities and the lifting of the previously strictly enforced headscarf ban, presumably a major obstacle for many women of lower-class origin to enrol. Moreover, with the establishment of new institutions in the poorer parts of the country, universities became more equally distributed across regions. This increased the enrolment of youth with diverse socio-economic backgrounds and reduced gender disparities on campuses (Gür 2016; Polat 2017).

The rapid expansion of higher education has escalated the debates about the quality of higher education and employment in Turkey. The availability of qualified academics and sufficient financial resources to build, for example, libraries and laboratories is questioned (Doğan 2013; Özoğlu et al. 2016; Polat 2017). Accordingly, there have been doubts as to whether the graduates of these universities are able to meet the demands of the labour market, given the currently high youth unemployment rate in Turkey at 25.2 per cent (ISSKUR 2019). These concerns are likewise raised in many middle- and low-income countries who have experienced rapid expansion (see: Schendel and McCowan 2016; Marginson 2016; Chang 2018.

\subsection{Higher education expansion and gender inequalities in the labour market}

\footnotetext{
${ }^{2}$ Foundation universities are non-profit foundations with the permission from the Council of Higher Education and must be confirmed by Parliament. Unlike public universities and although they charge high tuition fees.
} 
Higher education expansions in other contexts have often gone along with an increasing proportion of women entering the labour market (Chang 2018). However, this did not necessarily eradicate gender inequalities as new inequalities emerged within the workforce, such as gaps in career progression or wages, which are frequently linked to an emerging gender segregation in occupations that can be traced back to the choice of field of study (Steinmetz 2012). Such segregation often persisted with expansion (Barone, 2011; Charles and Bradley 2002). As far as gender segregation in employment is associated with the gender pay gap, such persistent segregation also contributes to persistent inequality with regard to pay. Fields typically chosen by women often pay less well in the labour market in comparison to natural sciences or technological fields, such as engineering or computer science, which are usually dominated by men (Barone and Assirelli 2019; Reimer et al. 2011, Reimer and Steinmetz, 2009). Different mechanisms could explain how segregation relates to the wage gap. The fields and subsequent occupations that women typically enter might equip them with human capital that is less demanded (Tam 1997). If the labour market is already strongly segregated by gender, the increasing influx of women into the highly skilled segment will lead to excess supply of typical female occupations and hence to a reduction of wages within these occupations ('crowding out', see Bergmann 1974). An alternative scenario is that the occupations typically chosen by women are not culturally valued and often include caring or nurturing tasks, which are the forms of unpaid work traditionally shouldered by women (England, 2010).

In the case of Turkey, where women with higher education were traditionally present in the labour force and segregation of higher education was lower than in most other European countries, both the crowding out and the devaluation mechanisms would require first an increase in the gender segregation of occupations. The rather small gender wage gaps among the highly educated before expansion further shed doubt on that a difference in specific human capital will cause a growing gender wage gap, if not higher education quickly segregates. Note also that the majority of the highly educated labour force is still from the time before the expansion and it is unlikely that their gender norms change rapidly, even with more traditionally minded graduates entering the workforce. Taking the specificities of the highly educated labour market into account, it would thus be less of a surprise if gender inequality in this labour market 
segment stayed at a moderately low level, if not gender segregation increases along with expansion. Moreover, while public childcare facilities are also relatively costly and are not widespread throughout the country (World Bank 2015), the large wage gap between workers with different level of education makes childcare arrangements comparatively easy for highly educated ones. Thus, it is first necessary to analyse the development of gender segregation within occupations, and without an increase in that strong changes towards more unequal pay should not be expected from the background of most explanations of gender inequalities in the labour market that are commonly put forward in Western societies.

Gender norms of the new students who traditionally stayed away from higher education are, however, a real threat to even highly educated women's labour force participation as soon as universities welcomed more traditional, religious women and for those from the least developed parts of the country. If women chose work-family models according to a norm-guided preference (Hakim 2001), more graduates from higher education might start seeking out more flexible working arrangements, ways to reduce the numbers of hours they work, or withdraw from the labour force entirely. While a higher level of education has been associated with more egalitarian gender values (Dryler 1998) and gender egalitarian values on the country level were shown to have little effect on occupational gender segregation (Dämmrich, 2014), the Turkish expansion might still lead to on average more conservative graduates since it is both massive and targeted at that part of population with particularly conservative values. Likewise, as a more highly skilled labour force emerges, gender inequality may develop in particular for the upper percentiles of the wage distribution if men have a higher probability of entering top jobs and a 'glass-ceiling' keeps women out of the best paying positions (see, Arulampalam et al. 2007; De La Rica et al. 2008).

In sum, the contribution of higher education expansion to the equalization of women will on the one hand depend on the potential of higher education to continuously warrant the participation of women in the labour market, as well as equal access to positions with high wages. In light of the increasing demand of academically trained employees due to the economic boom and the teacher recruitment for the expansion of secondary education, this could be expected in the case of Turkey. At the same time, occupational gender 
segregation must stay at a low level. It is thus key to describing the development of gender segregation over time to understand possible changes in gender inequalities among higher education graduates. On the other hand, the changing selection of different parts of the Turkish population and the inclusion of more traditional and often lower class young adults within higher education - which might contribute to other aspects of equalization - can potentially reduce the contribution to gender equalization. Together with questions about the quality of higher education under rapid expansion of institutions and a possible excess supply of graduates in light of the very fast increase in the number of enrolments, this might slow down or even reverse gender equality through higher education.

\section{Data and Methods}

Our analyses were based on cross-sectional trend data of the Turkish Household Labour Force Survey (THLFS) for the years 2005, 2008, 2011, 2014 and 2017. In order to capture the labour market situation of the most recent cohorts - that is, those affected by the expansion - we limited our sample to 26 to 28 yearolds for each survey wave we analysed. At this age, most young adults have completed higher education and initial qualifying labour market activities, such as traineeships. It should also be emphasized that the situation around the time of the labour market entry is often an important determinant for the later working career (e.g., Blossfeld et al. 2014; Author C, 2015).

We harmonized all concepts over time in order to make trend analysis possible. While some concepts changed from year to year or were asked in different categories, the overall question programme of the survey remained rather consistent. Since the THLFS is a household sample, we applied the design weights provided by TurkStat throughout our entire analyses.

As a first step, we showed the expansion of higher education over the time period we describe. Second, we illustrated the development of women's employment rate and refined this picture by creating a variable that shows who stops actively searching for employment due to household obligations. We modelled the 
participation in the labour force as well as staying at home for family reasons as logistic regressions and decomposed the trends of these activities among women into a component that stems from the correlation of this trend with the increasing number of women with higher education and all other developments applying the detailed decomposition method suggested by Yun (2004). This allowed us to evaluate the contribution of the weakening link between higher education and labour market participation to the increase in female employment rate. THLFS data is comparatively sparse when it comes to measures of a general change in gender attitudes over cohorts, which might drive the increase of working women especially among the highly educated population. We thus added changing marriage patterns as a proxy for changing gender relations to the model in order to show that the contribution of the higher education expansion is robust to such processes, even though the decrease in the proportion of married women itself may partly be affected by the increasing educational level.

Third, we described the development of occupational sex segregation for graduates from higher education. As operationalization for segregation we mainly employ the segregation index devised by Duncan and Duncan (1955) that relies on the proportion of the sample that would have to be reshifted to achieve an equal distribution across genders. We calculate the index based on the first two digits of the international standard classification of occupations (ISCO) since a more detailed version was not available in the dataset. As the ISCO classification changes from the 88 to the 08 version between the waves in 2011 and 2014, we converted the occupational codes to the respective other classification for all waves and calculated the Duncan-index for each of them.

Fourth, we described the development of the gender wage gap over time. We relied on the monthly wage information from labour sources in the LFS and adjust all wages for inflation to the value of the Turkish Lira on Jan 1, 2017. Wage information was based on the monthly earnings of individuals from their main job, including their monthly salary, bonuses, premiums, etc. 
As can be seen in table 1, the number of cases allows for a comparatively precise description of the abovementioned developments. The sub-analyses for the northern region are a potential exception as the case numbers here are somewhat smaller.

Table 1: Number of cases

\begin{tabular}{lcccc}
\hline Year & Total (Turkey) & West & North & East \\
\hline $\mathbf{2 0 0 5}$ & 23,116 & 15,729 & 2,851 & 4,536 \\
$\mathbf{2 0 0 8}$ & 23,951 & 16,153 & 2,603 & 5,195 \\
$\mathbf{2 0 1 1}$ & 33,470 & 15,754 & 2,457 & 4,259 \\
$\mathbf{2 0 1 4}$ & 20,794 & 13,276 & 2,320 & 5,198 \\
$\mathbf{2 0 1 7}$ & 18,352 & 11,761 & 1,798 & 4,793 \\
\hline Total & 108,683 & 72,673 & 12,029 & 23,981 \\
\hline
\end{tabular}

\subsection{Regional sub-analyses}

Although Turkey has seven geographic regions, social scientists often only distinguish five regions, the West, South, Central, North, and East (Author B, 2016; Smits \& Gündüz-Hoşgör, 2006). Among these, West, South and Central are identified as more 'westernized' and developed in terms of their industrial and infrastructural advancements as compared to North and East (Gündüz-Hosgör \& Smits, 2007). Accordingly, only a few cities in these two regions had a university before the expansion in 2006, while the majority of the cities in the more developed three regions had at least one university (see figure 1). Thus, the North and the East have been affected greatly by the recent expansion of higher education in terms of the availability of higher education. Therefore, we conduct regional sub-analyses for these two cases and combined the other three regions into one large region 'West'. Based on the Nomenclature of Territorial Units for Statistics (NUTS) 1 regions, we combined the West Black Sea and East Black Sea regions into the North, and Central East Anatolia, Northeast Anatolia and Southeast Anatolia regions into the East.

Figure 1: Turkish macro regions for separate analyses 


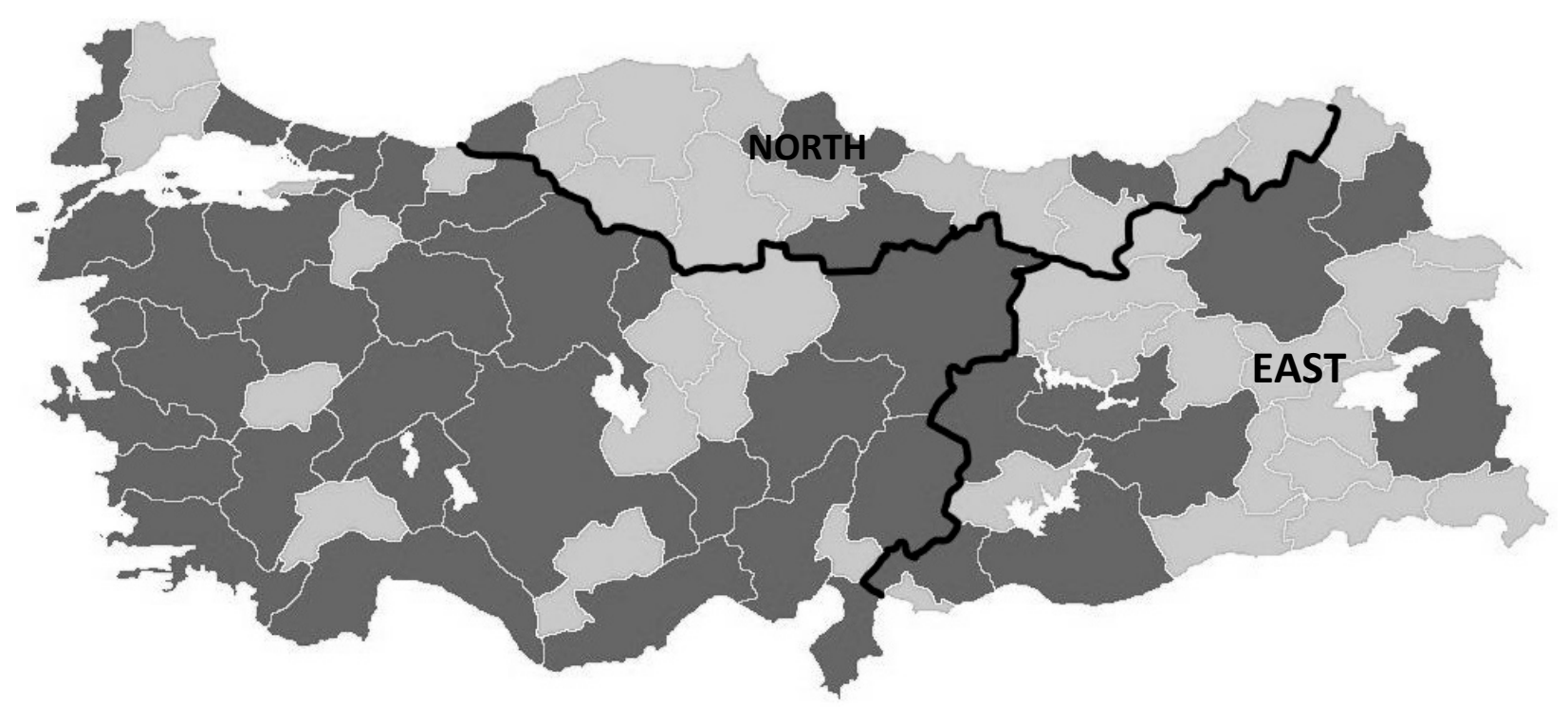

Note: Grey provinces did not have a university before 2006. Now, each province has at least one university. Source: Adapted from Gur (2016), macro-regional boundaries added by authors.

\section{Results}

\subsection{Expansion of higher education}

In line with previous research, our data shows a rapid expansion of higher education in Turkey in recent years. Figure 2 shows a very sharp increase in the proportion of young people with a degree in higher education for both genders in the age group from 26 to 28 : it more than doubled for men within only 12 years, and it almost tripled for women over the same period. With this rapid increase for women, especially in the last years, the proportion of women with a degree in higher education overtook the proportion of men with the same for the selected age group.

Figure 2: Proportion of 26- to 28-year-olds with a completed degree in higher education between 2005 and 2008, by gender. 

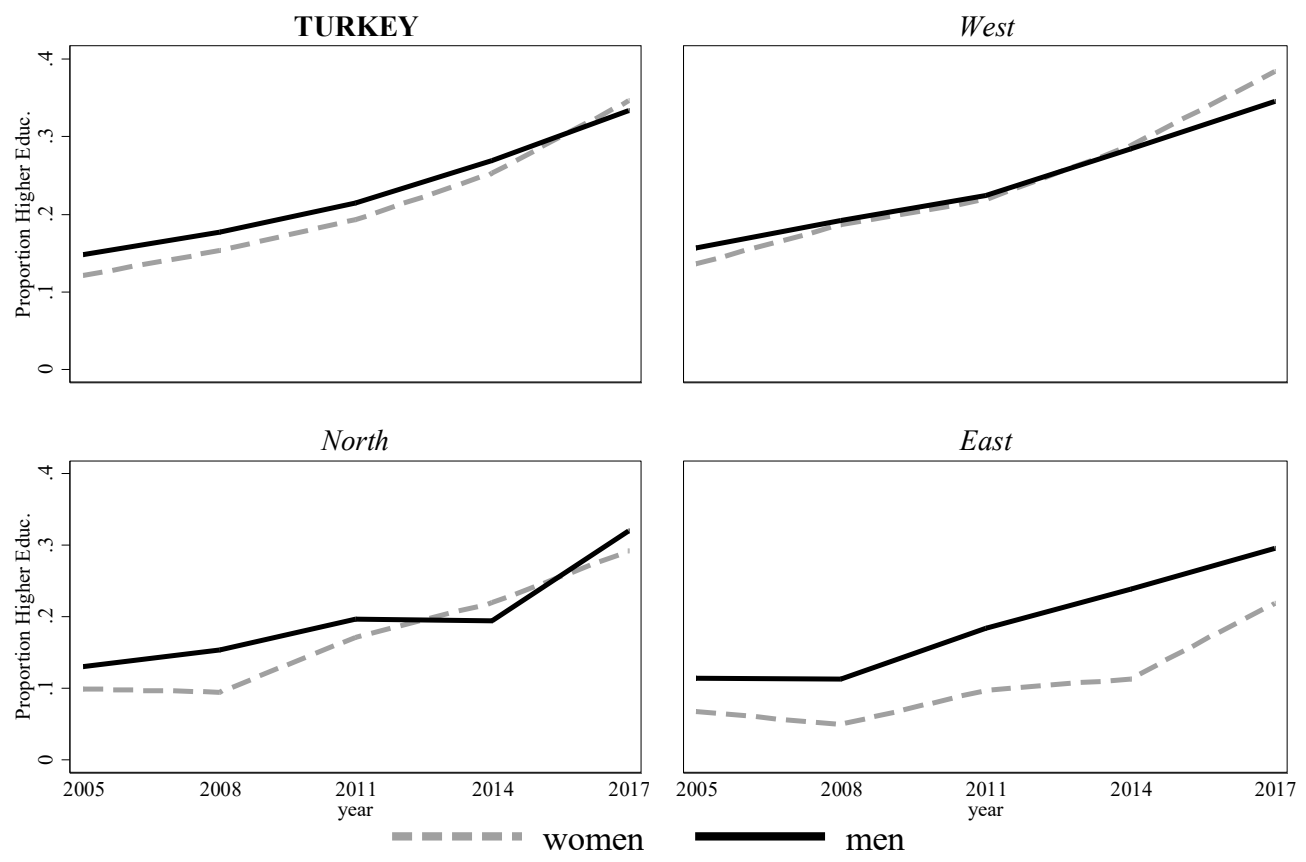

N 108,683; THLFS, own calculations

Sub-analyses for the three regions illustrate the geographic differences among highly educated young adults. The North and the East saw an expansion that was at least as fast as in the rest of the country, but from a lower starting level. In addition, gender differences are quite different from the overall pattern. The gender gap in higher education attainment in the western regions was not large before the expansion, while there had been gender inequality in the East and the North. The gap in the North almost closed over the course of the expansion, but persisted in the East even though there was a general expansion of higher education for both genders there, too.

\subsection{Women's labour force participation}

In terms of overall labour force participation of young women in Turkey, our results indicate a clear and steady upward trend (see figure 3): there is an increasing number of women in work. The rate for the country 
overall has increased from 27 per cent in 2005 to 39 per cent in 2017. Again, the northern and eastern provinces are in a somewhat different position compared the western parts of Turkey. Female labour force participation was already high before this period, but did not increase further in the North. In the East, on the other hand, women have traditionally stayed at home, which is reflected in the low overall participation rate. However, an increase from 16 per cent in 2005 to almost 28 per cent in 2017 shows that the situation has recently started to change.

Figure 3: Proportion employed by gender, 26- to 28-year-olds
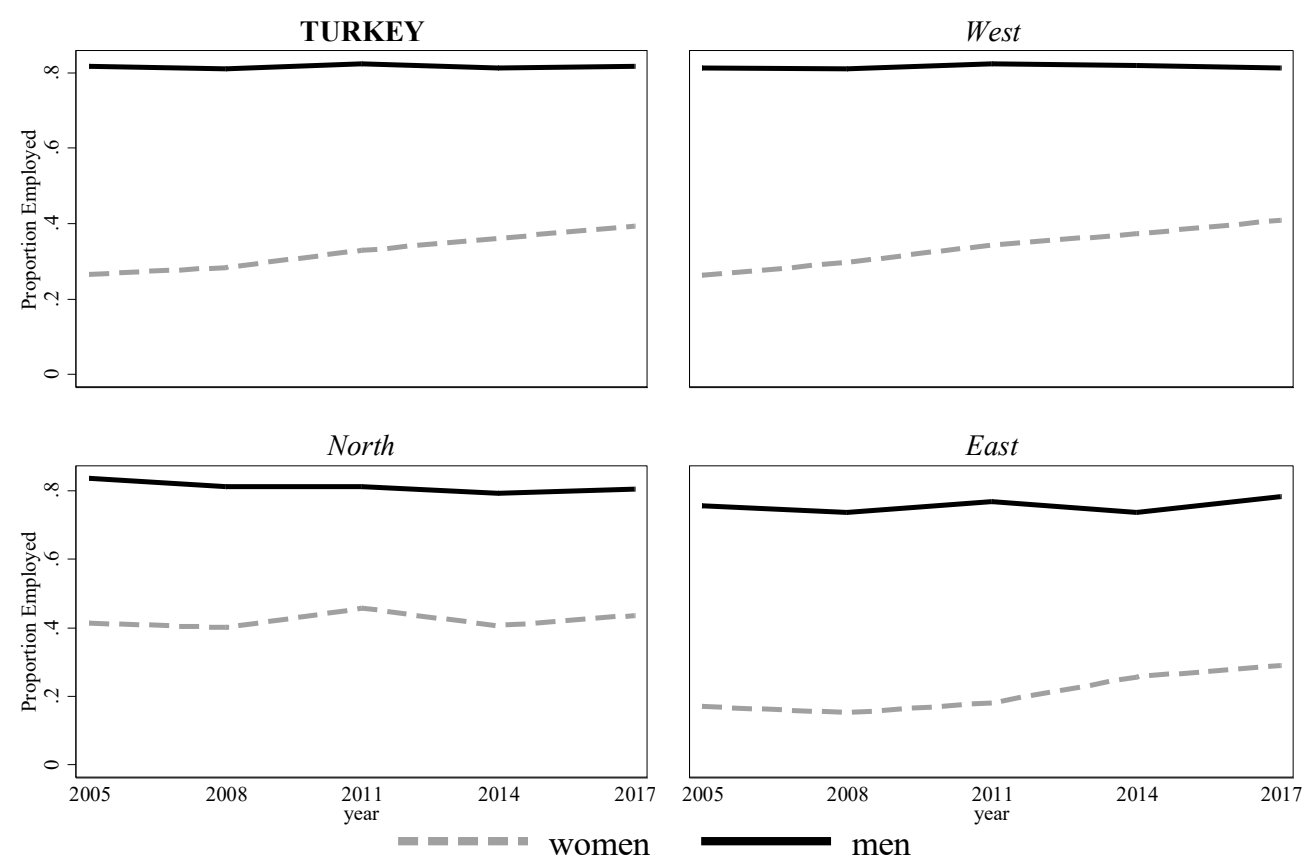

N 108,683; THLFS, own calculations

When we differentiate by higher education attainment, we find that expansion in higher education cannot be the only reason for the overall increasing share of women in gainful employment since the number of working women without a degree in higher education is also increasing. Employment rates of women with a higher education degree even decrease somewhat. This decrease might to some degree be expected due 
to the changing selection into higher education, especially for women - meaning that different women enrol in higher education due to expansion and the lift of the headscarf ban, that is, more women with traditional gender values from less developed parts of the country. The employment gap between women with and without a higher education degree remains very high, with an approximate 28 percentage point difference in 2017. Thus, the net contribution of higher education expansion to the increase of women's employment should still be positive due to the strong increase in the number of women with a tertiary qualification and the continuously high probability of working.

Figure 4: Proportion employed by gender and higher education attainment, 26- to 28-year-olds
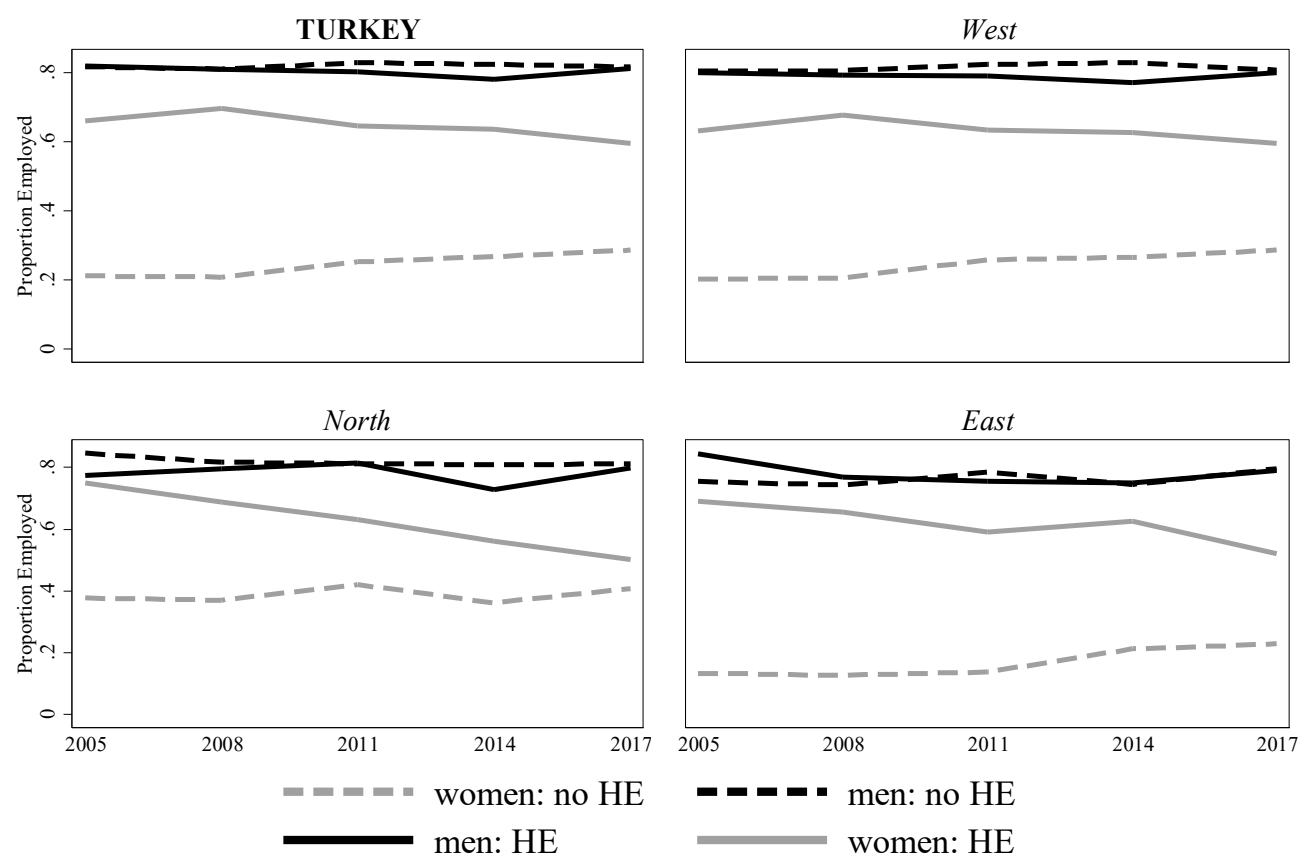

N 108,683; THLFS, own calculations

Breaking down the employment trend by region shows that there has been a significant decrease in employment rates amongst women with a higher education degree in the two regions where higher education capacities were built up from the lowest starting levels. As discussed previously, the East and the 
North are also the least industrialized regions of Turkey. Therefore, there may either not be enough jobs for highly educated people in these regions, or the influx of large proportion of women with more traditional family values counteracts the gain in employability that usually goes alongside higher education. The factors might also work in combination, if women withdraw from the workforce in the case of a bad labour market outlook more quickly than men since, for them, becoming a homemaker is a socially acceptable alternative. It is also worth mentioning here that the increase in the number of graduates in these two regions is mostly driven by newly established universities, whose quality has been frequently questioned.

Figure 5: Proportion withdrawing from the labour market for family reasons by gender, 26- to 28-year-olds
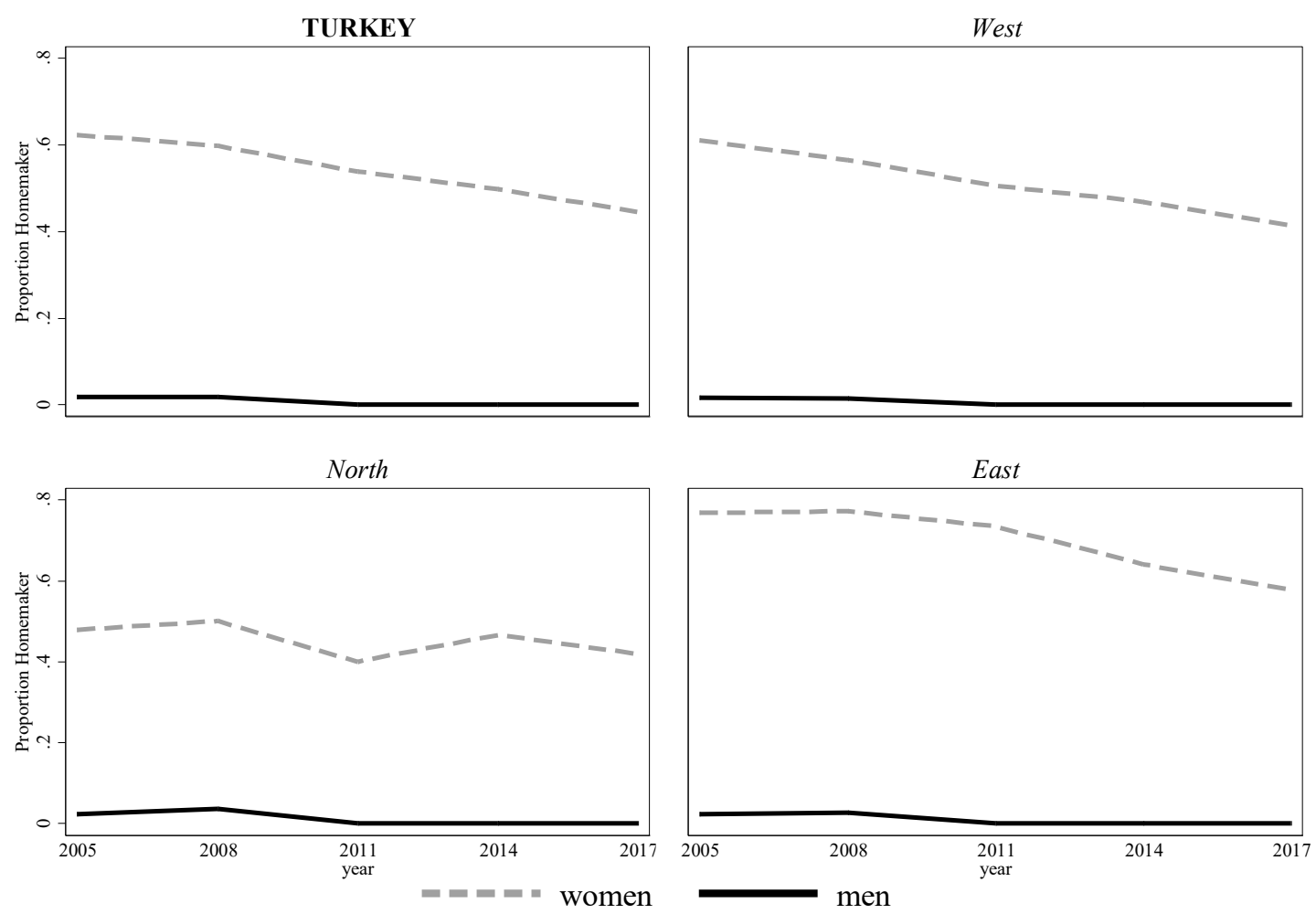

N 108,683; THLFS, own calculations

In figures 5 and 6 , we show the rates of withdrawal from the labour market for family reasons by gender and higher education status (figure 6). The proportion of young women who stay at home due to household obligations has decreased significantly (about 18 percentage points) over the last decade. For higher 
education graduates, the proportion increased at the same time to a smaller degree from 13.9 per cent to 16.7 per cent and decreased for non-higher education graduates from 69.1 per cent to 59.4 per cent, which shows that only a part of the general trend towards economic activity of women in the labour market is due to the expansion of higher education. The gap between women with and without a higher education degree is still very high (42.7 percentage points). Men, by contrast, stay completely away from this role, regardless of their level of education. This shows how the process of change is mainly moved by the action of women, and that the traditional gender roles of men have seemed to survive.

Figure 6: Proportion withdrawing from the labour market for family reasons by gender and higher education attainment, 26- to 28-year-olds
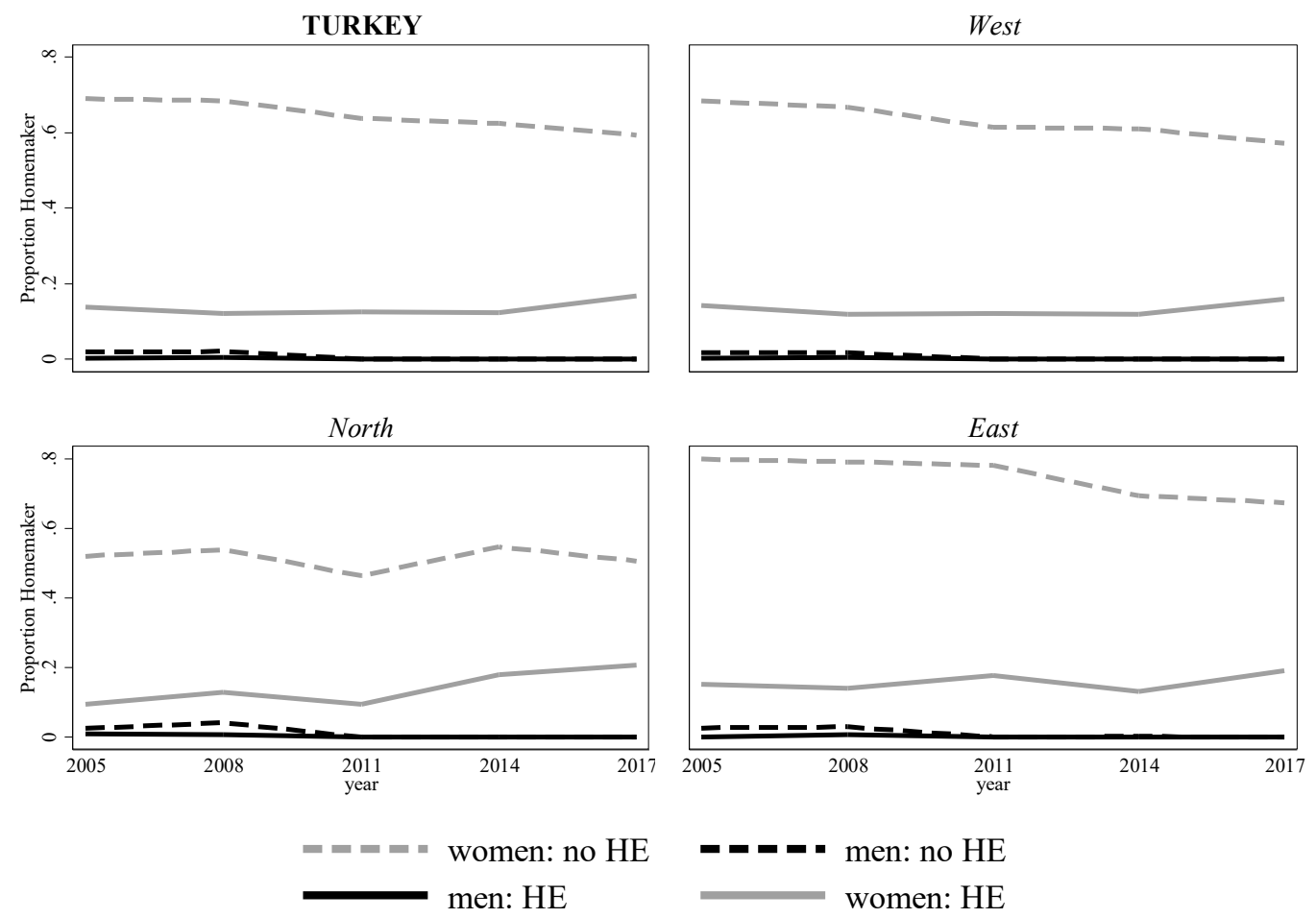

N 108,683; THLFS, own calculations

Regional sub-analyses again corroborate our findings for employment: eastern Turkey is clearly more traditional, but has recently been undergoing a particularly rapid change. In the North, women are traditionally less often adopting a homemaker role, but there is also not much change over time. Figure 6 
shows that the regional differences are almost irrelevant for highly educated women, who have rarely stayed at home from the beginning of our observation period, even in the East. The exception is the development in the North of Turkey, where the rate at which women with a higher education degree who stay at home is increasing particularly fast. This is interesting in light of the fact that female labour force participation is traditionally common in this region; it could point towards challenges within the labour market to absorb the large number of graduates.

Finally, we want to quantify the contribution of the expansion of higher education to the increase in female labour force participation between 2005 and 2017. In a decomposition analysis based on a logistic regression, we separate the proportions of the overall development into a component that was changed due to more women with higher education, and another component that is driven by the decreasing gaps in employment or withdrawal of women with and without higher education. A multivariate decomposition analysis further allows us to analyse the contribution of other structural changes over this period. We include the decline of marriage as an indicator of the general modernization into a second model.

Table 2: Results of detailed compositions (logistic regression) of the change in women's labour force participation and the choice to withdraw from the labour market in order to care for the family ('homemaker')

\begin{tabular}{|c|c|c|c|}
\hline & 2005 & 2017 & Change \\
\hline $\begin{array}{l}\text { Change in covariates } \\
\text { proportion: higher education } \\
\text { proportion: married }\end{array}$ & $\begin{array}{l}0.121 \\
0.765\end{array}$ & $\begin{array}{l}0.346 \\
0.695\end{array}$ & $\begin{array}{l}0.225 \\
-0.069\end{array}$ \\
\hline $\begin{array}{l}\text { Decomposition: increase in employment } \\
\text { proportion: employed }\end{array}$ & 0.266 & 0.394 & 0.128 \\
\hline $\begin{array}{l}\text { Model } 1 \text { (ref.: 2017): } \\
\text { Higher education: endowments } \\
\text { Higher education: coefficients }\end{array}$ & & & $\begin{array}{l}54.4 \% \\
-11.76 \%\end{array}$ \\
\hline $\begin{array}{l}\text { Model } 2 \text { (ref.: 2017): } \\
\text { Higher education: endowments } \\
\text { Higher education: coefficients } \\
\text { Married: endowments } \\
\text { Married: coefficients }\end{array}$ & & & $\begin{array}{l}43.4 \% \\
-10.7 \% \\
10.5 \% \\
-22.3 \%\end{array}$ \\
\hline $\begin{array}{l}\text { Decomposition: decrease in being a homemaker } \\
\text { proportion: homemaker }\end{array}$ & 0.623 & 0.446 & -0.178 \\
\hline
\end{tabular}




\section{Model 1 (ref.: 2017):}

Higher education: endowments

Model 2 (ref.: 2017):

Higher education: endowments

$38.0 \%$

Higher education: coefficients

$-9.9 \%$

Married: endowments

$14.9 \%$

Married: coefficients

$-23.9 \%$

\section{$\mathrm{N}: \mathbf{2 1 , 6 0 5}$}

*holding constant for the exact age within the sample. Source: THLFS, own calculations.

The results of models 1 and 2 suggest that approximately half of the overall increase in female employment or decrease in withdrawing from the labour market for family reasons is related to the increasing number of women with a degree in higher education (see: endowments). On the other hand, in the rows labelled 'coefficients' for model 1 , for both dependent variables we can see that the loosening connection between higher education and labour market participation reduces the overall trend towards increased female employment through the modest decrease in labour force participation by women with a degree in higher education. In the second model, we add marriage behaviour to model. This reduces the share of the increase in female labour force participation that can be explained by higher education somewhat. The reduction is even a bit stronger for the probability to stop searching for work and becoming a homemaker, which makes sense given the close connection of the traditionally gendered division of work and marriage. Still, and even though a part of the decrease in marriage could be endogenous to the increase in higher education, there remains a substantive part of the increase that we attribute to the expansion of higher education. It is also noteworthy that the change in the probability of getting married ('married: endowments') is much smaller in its contribution to the increase in women's labour market participation, which again should give us confidence that the contribution of the higher education expansion was non-trivial. Interestingly, the 'coefficients' contributions hardly change for higher education. They are, on the other hand, much stronger for marriage, indicating that the relationship between working and labour market entry tightened while 
fewer women get married. This result should motivate further research into the change of opinions towards gender relations and women's roles in the society.

Overall, while these results certainly lack a broader set of controls, especially regarding changing family values, they point towards a significant role of the higher education expansion in raising female labour force participation. Even though the selection into higher education is certainly changing once the system opens up to a larger share of a cohort - including academically weaker students - and with the increasing attraction of higher education to more traditional groups, it still maintains its role as an entry ticket into employment for women.

\subsection{Gender segregation among the highly educated}

The growing number of graduates from higher education raises questions about the gender divide within the highly skilled labour force. Segregation into different fields of studies are known as a very persistent pattern for economically advanced societies. As discussed above, both horizontal and vertical gender inequalities in the labour market were weak in the highly skilled sector of the Turkish labour market. But can that hold with an increasing influx of women and a generally fast-growing population of graduates? There are a few pointers that do suggest rather small changes. From 2011 on, our data contains information about the fields of study in higher education, and in the time until 2017 the differences between men and women in the STEM-fields remains stable. While 45.9 per cent of men graduated from a STEM-field in 2011, the corresponding number of women was 18.4 percent. Although this can be seen as a pronounced difference, it remained stable at least until 2017 when the shares were 44.0 percent for men and 18.5 percent for women.

A more global measure of segregation is the segregation index by Duncan and Duncan (1955). We calculate the index for occupations, not fields of studies, as operationalization of segregation in the labour market. As can be seen in figure 7, gender segregation has been very stable over time for both classifications (see 'Data and Methods'), indicating no meaningful change in occupational segregation during the expansion. 
The index value always stays close to 0.30 , which means that it would need a shift of ca. 30 per cent of the respective population to another occupation in order to achieve gender inequality in the labour force. It should be noted that this value is a relatively low level of occupational segregation compared to most European countries (Smyth \& Steinmetz, 2008, p 259), which typically range between 0.45 and 0.50 . Thus, the labour market has not (as yet) segregated more into gender-specific occupational spheres than used to be the case before the expansion, and has rather stayed at a moderate level by international comparison.

Figure 7: Duncan-index of segregation for the occupational gender segregation among highly educated labour market entrants between 2005 and 2017, 26- to 28-year-olds

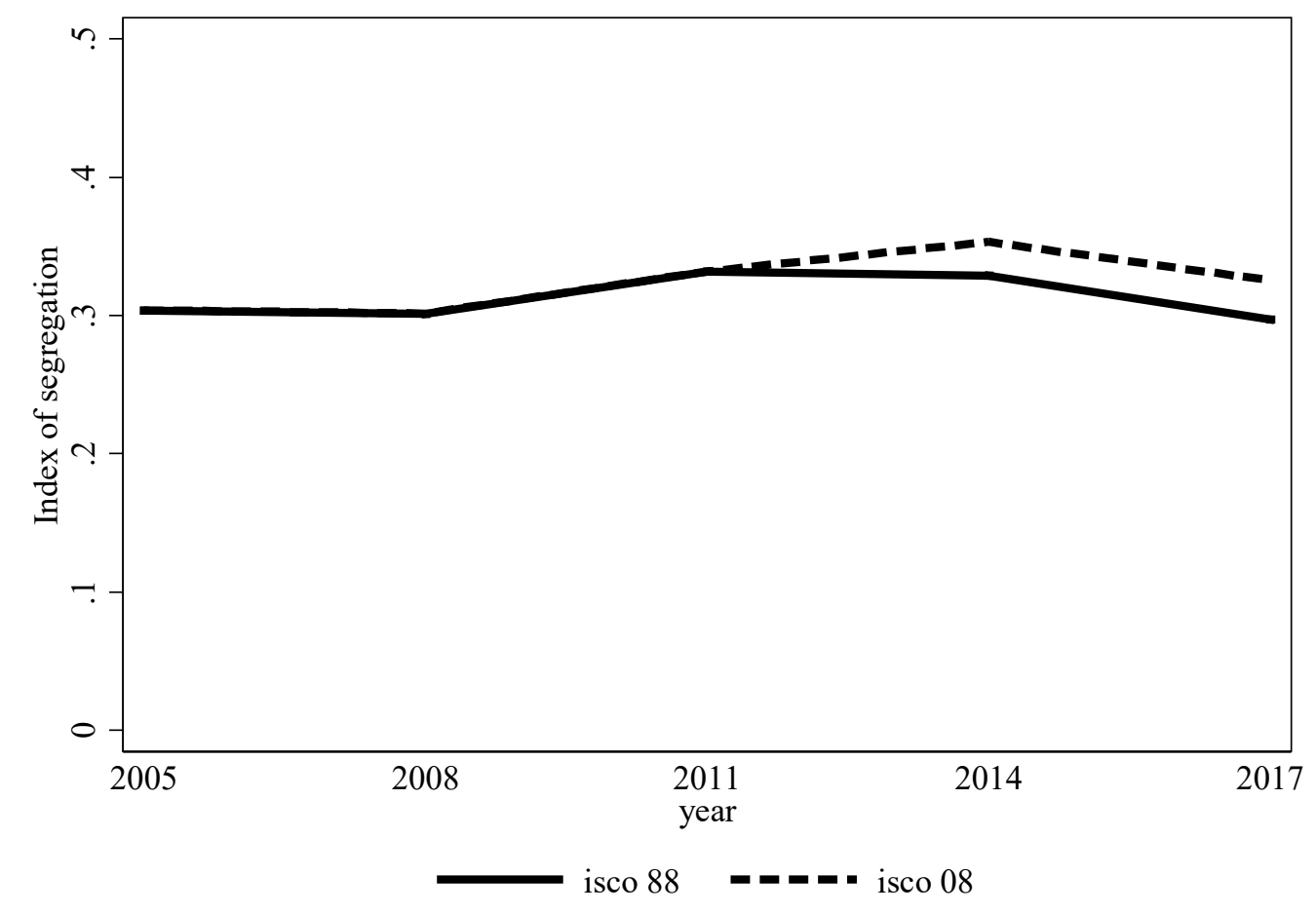

Data source: THLFS, own calculations

On the other hand, there are still many Turkish women who work as unpaid family members - a position that signals a high degree of dependence on the husband, parents or parents-in-law. We observed above that with educational expansion more women with higher education stayed at home and took care of the family. 
It could thus also be expected that higher education would become less and less of a way out of unpaid family work. We thus investigated the trend in unpaid family work by gender and higher education in figure 8. The proportion of unpaid family workers is very low, close to zero, for women with a degree in higher education. There is no increase over time for this comparatively dependent type of work, despite the significant increase in the proportion of women with a degree in higher education. That means that higher education still helps almost all women who complete a degree to avoid unpaid family work. This holds even for the most traditional, conservative and agricultural regions in the east and the north of Turkey. It also suggests that families do not expect women to be involved in unpaid family work after higher education, even if they are unemployed. Of course, this might to some extent also reflect the fact that highly educated women are more likely to be married to highly educated men, who are usually not running smallscale family farms.

Figure 8: Being an unpaid family member by higher education attainment and gender, 26- to 28-year-olds
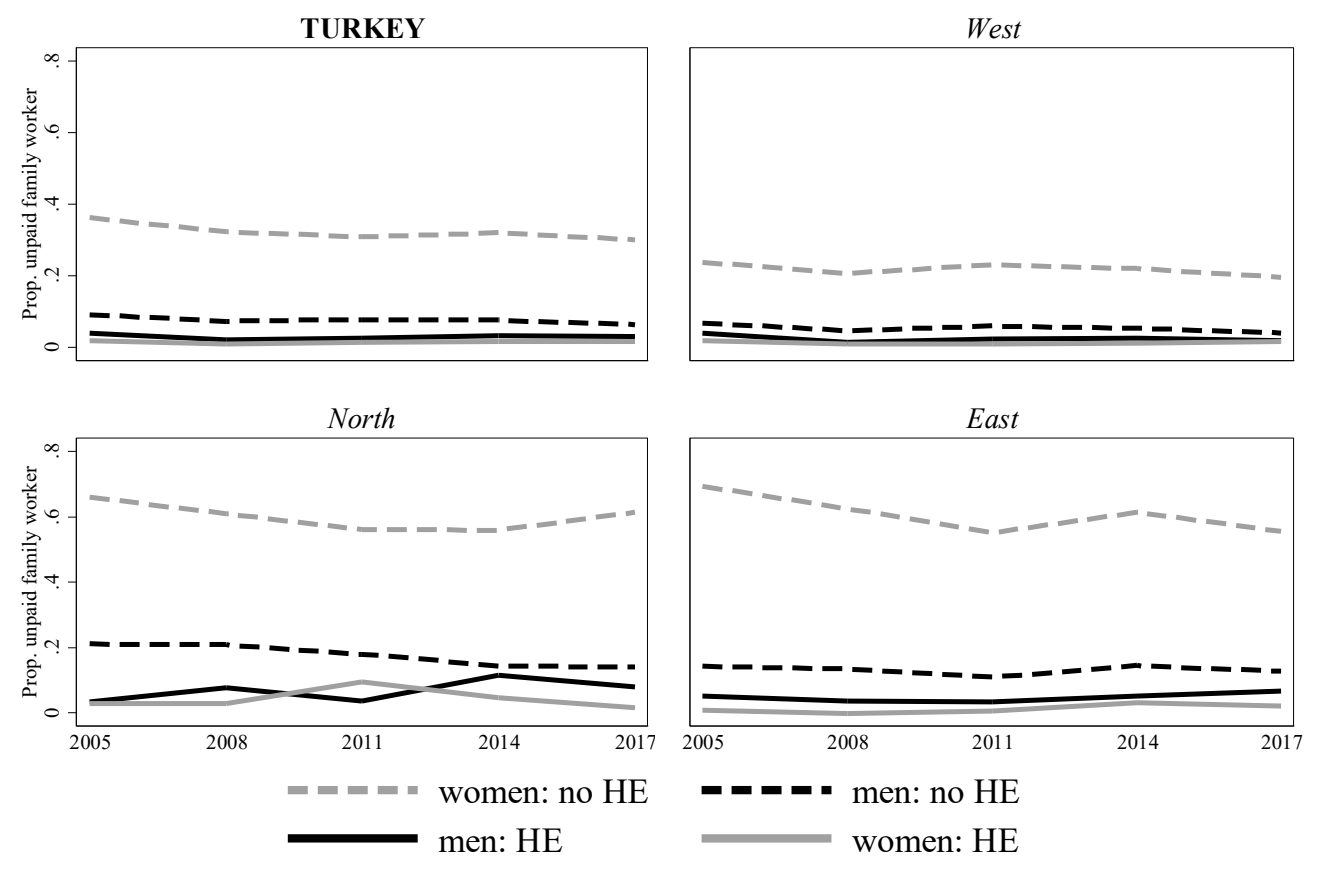

Data source: THLFS, own calculations 
Overall, we would thus conclude that important dimensions of segregation in the labour market are surprisingly stable, and remain at a moderately low level even if we assume that the population of graduates from higher education changes due to a less selective admission and a more welcoming environment towards young people with conservative attitudes.

\subsection{The gender pay gap among the highly educated}

The stable segregation is a first pointer that the gender wage gap might also remain the same during the expansion. Figure 9 reports the development of median, first and third quartile wages for young people with and without a higher education degree from 2005 to 2017. First, it documents a significant wage gap between workers with versus those without higher education. However, this gap became slightly smaller after 2014 since the median wage for labour market entrants with higher education decreased, while it increased for those without higher education. It is also evident from the figure that gender pay gaps are relatively small for both educational groups in comparison with most European countries (cf. Christofides et al. 2013).

The wage discrepancy by gender amongst the highly skilled labour market entrants is growing mostly at the upper end of the distribution, the $75^{\text {th }}$ percentile (uppermost lines for each group), in the most economically developed regions of Turkey. This might be a sign of a developing glass ceiling, i.e., that women do not gain access to the best paid positions as often as men. While even this gap is still not very large by comparison to other countries, it should be a focus for future research. Wage differences at the first quartile, on the other hand, barely exist and do not change over time.

Figure 9: Development of median, first and third quartile wages by higher education attainment and gender, 26- to 28-year-olds 

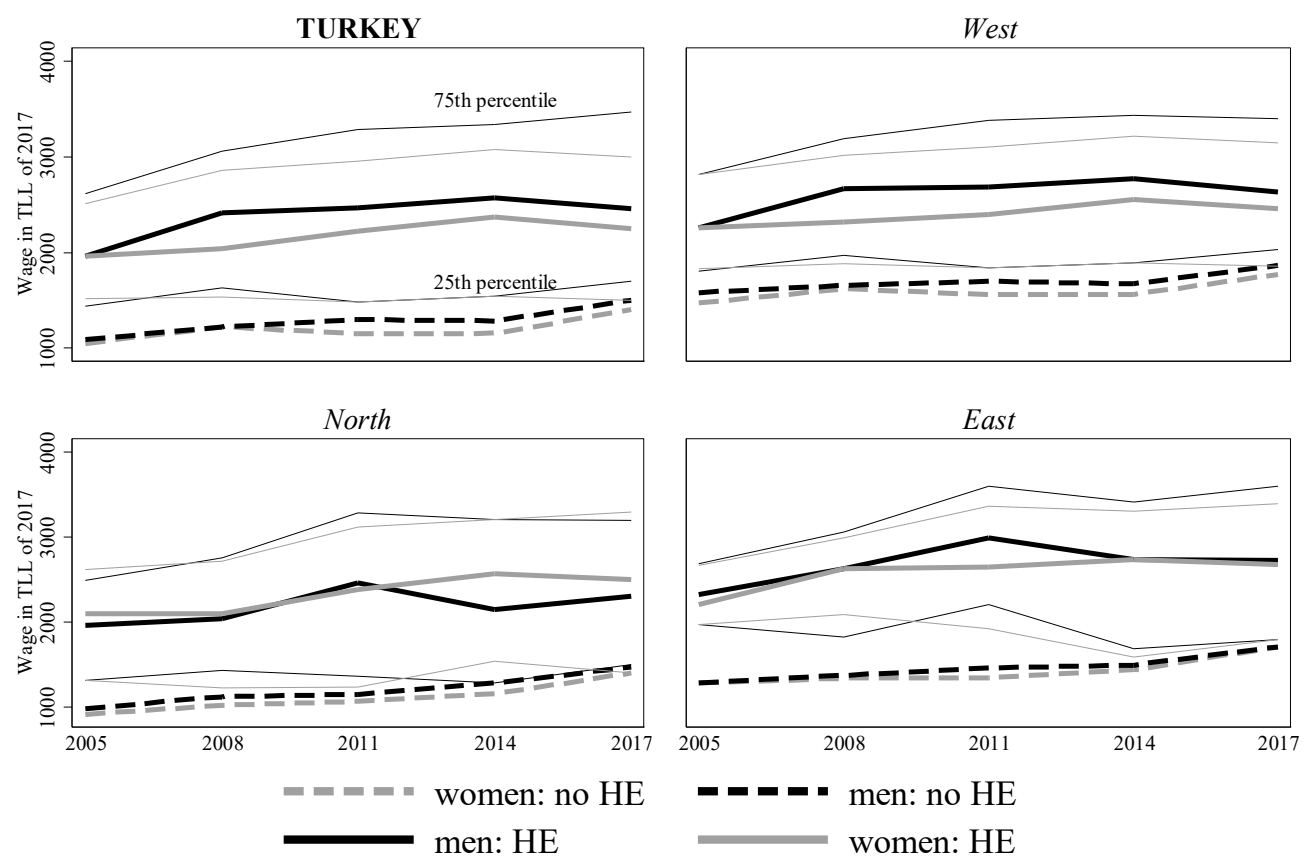

Data source: THLFS, own calculations

Regarding regional differences, we find that the situation in the West mostly echoes the overall figure for the country while there are smaller and mostly inconsistent gender pay gaps in other regions. The wellestablished gender pay gap in the West is perhaps related to the strong private sector and male-dominated business activities such as large construction companies in this region. Another interesting case in terms of the gender pay gap for higher education graduates is the general tendency towards higher earnings amongst women in the North. This is surprising since the typical work for women in this region is in agriculture, and unemployment amongst women with higher education has recently been increasing there.

\section{Discussion and Conclusion}

In this article, we describe trends in gender inequality in the labour market during the rapid expansion of higher education in Turkey using data from the Turkish Household Labour Force Survey (THLFS). We 
specifically focussed on three dimensions of inequality: women's participation in the labour force, occupational gender segregation, and the gender wage gap, all of which are underpinned by Sustainable Development 5 Goals for ensuring women's full and effective participation in economic life.

In line with the trend in higher education expansion across the world, women's participation in higher education in Turkey has increased faster than that of men (See Chang 2018). The gender gap in higher education has been closed, or even reversed in favour of women. The exception to this trend was eastern Turkey. One reason for this could be the resilience of conservative values and traditional gender norms in relation to women's education in this area. Our results also show that the expansion plays an important role for the increase in women's participation in the labour force. While existing research in Turkey has already shown that women with higher education have significantly higher levels of labour force participation (Atasoy 2017; Dildar 2015), we confirmed this trend even though the expansion was extremely fast.

However, the gender gap in employment cannot be assumed to be the sole indicator of gender equality as this would overlook other inequalities such as the unpaid domestic and care work. Our analysis shows that a much smaller proportion of women with higher education withdraw from the labour market for family reasons compared to women without higher education. Although there has been a small increase in the proportion of homemaker-women with higher education in recent years, especially in eastern Turkey, our decomposition analysis shows that the net effect of the expansion of higher education on women's tendency to stay at home is still positive. While a higher education degree helps significantly, the results also show that more women than men still give up their careers due to household obligations, regardless of their level of education. This is some indication for the influence of traditional breadwinner roles of men in the Turkish society. In addition, a significant proportion of women who benefited most from the higher education expansion in Turkey probably comes from rural areas with on average lower SES and more conservative backgrounds. It is thus not a surprise that now less graduates from higher education participants enter the labour force, either due to their choices to care for their children and/or family or due the anticipation of discrimination against women in the labour market that is sometimes directed specifically against women wearing headscarves (Cindoglu 2011). 
Occupational gender segregation has remained stagnant over the years in Turkey, with men being particularly overrepresented in STEM-related fields of study. In spite of the decades-long debate, it seems that occupational sex segregation still hasn't changed. However, it should not be forgotten that the gender segregation in Turkey is relatively low by international standards and has not, at least, increased with the rapid expansion of higher education and the growth of the teaching profession during the expansion of secondary education, as one might otherwise expect. Moreover, the existing gender segregation has not lead to a large gender wage gap by international comparison (Addabbo and Favarozo 2011; Assirelli 2015). Although there is a wage gap between highly educated workers and workers with low levels of education, the wage discrepancy between highly educated men and women is not very large and mostly visible, and indeed increasing, at the $3^{\text {rd }}$ quartile of the distribution. This might indicate an emerging 'glass ceiling'effect, meaning that women are specifically underrepresented in the best paying jobs (Cotter et al., 2001). As an overall judgement, the finding that higher education loses little of its potential to integrate women into a labour market segment with a small gender wage gap in spite of the changing selection into universities supports those theoretical hypotheses that highlight the potential for equalization represented by higher education expansion. Gender role attitudes seem to be less influential than the opportunities that women gain with higher education.

This study provides the first exploration of the relationship between the trends of higher education expansion and changing gender inequalities in Turkey. The effects of the higher education expansion have been at the centre of many debates but have previously lacked empirical insights into the arising trends of gender inequality in the labour market. To this end, our analysis highlights the importance of expansion for widening participation. We also find a few developments that point in the other direction, e.g. that slightly more women with higher education have withdrawn from the labour force in recent years. While this is also a noteworthy development, it is by far outweighed by the strong growth in the proportion of women who chose to work as a consequence of the expansion of higher education.

The developments described in this article may have long-term consequences for the Turkish society in several respects. While a fast and complete equalization of women and men cannot be expected in the near 
future, one could well speculate that the growing number of economically independent women will also change public opinion and make a lasting impact due to the present expansion of higher education very likely. There are also, however, a number of issues that could become more problematic over time. While we now observe little change to the relatively gender-equal labour market for highly educated women, this might well change in the future, for example if the growing share of women in some occupations leads to a devaluation of their average wages. In particular, the scarcity of public childcare or publicly financed parental leave might in the long run - when private childcare inevitably gets more expensive - become a major challenge for women (and men) who want to combine a working career with their family formation. To this end, the expansion can also have effects on the demography of Turkey that are not, as yet, on the agendas of researchers and policy makers, namely increasing decreasing fertility rates, later childbearing and as a consequence of the fewer children and the more economically independent women, potentially also higher divorce rates. Thus, it will be important for future research to follow these developments closely. Finally, it will be important to keep a close view in particular on the eastern and northern regions of Turkey, which come from particularly high levels of gender inequality, with comparatively conservative family values, and which face additional challenges due to lower economic development. Highly educated women in these regions are also much better off than women without higher education, but are still less often able to turn their degree into employment as in other parts of the country, at least if they do not move away from their hometowns. 


\section{References}

Author A, 2017

Author B, 2016

Author C, 2015

Addabbo, T., \& Favaro, D. (2011). Gender wage differentials by education in Italy. Applied Economics, 43(29), 4589-4605.

Ahmed, R., \& Hyndman-Rizk, N. (2018). The higher education paradox: towards improving women's empowerment, agency development and labour force participation in Bangladesh. Gender and Education, 1-19.

Arulampalam, W., Booth, A. L., \& Bryan, M. L. (2007). Is there a glass ceiling over Europe? Exploring the gender pay gap across the wage distribution. ILR Review, 60(2), 163-186.

Assirelli, G. (2015). Credential and skill mismatches among tertiary graduates: the effect of labour market institutions on the differences between fields of study in 18 countries. European Societies, 17(4), 535-568.

Atasoy, B. S. (2017). Female labour force participation in Turkey: The role of traditionalism. The European Journal of Development Research, 29(4), 675-706.

Barone, C. (2011). Some things never change: Gender segregation in higher education across eight nations and three decades. Sociology of Education, 84(2), 157-176.

Barone, C., \& Assirelli, G. (2019). Gender segregation in higher education: an empirical test of seven explanations. Higher Education, 1-24.

Bergmann, B. R. (1974). Occupational segregation, wages and profits when employers discriminate by race or sex. Eastern Economic Journal 1(2): 103-110.

Chang, D. F. (2018). Effects of higher education expansion on gender parity: a 65-year trajectory in Taiwan. Higher Education, 76(3), 449-466.

Cindoğlu, D. (2011). Headscarf ban and discrimination: Professional headscarved women in the labor market (p. 14). Istanbul: Tesev Publications.

Charles, M. and K. Bradley (2002). Equal but Separate? A Cross-National Study of Sex Segregation in Higher Education. American Sociological Review 67(4): 573-599.

Christofides, L. N., Polycarpou, A., \& Vrachimis, K. (2013). Gender wage gaps, 'sticky floors' and 'glass ceilings' in Europe. Labour Economics, 21, 86-102.

De la Rica, S., Dolado, J. J., \& Llorens, V. (2008). Ceilings or floors? Gender wage gaps by education in Spain. Journal of Population Economics, 21(3), 751-776.

Dildar, Y. (2015). Patriarchal norms, religion, and female labor supply: Evidence from Turkey. World Development, 76, 40-61.

Doğan, D. (2013). Yeni kurulan üniversitelerin sorunlari ve çözüm önerileri. Journal of Higher Education and Science 3(2): 108-116.

Dryler, H. (1998). Parental role models, gender and educational choice. British Journal of Sociology 49(3): 375-398.

Duncan, O. D. and B. Ducan (1955). A methodological analysis of segregation indexes. American Sociological Review 20(2): 210-217.

Dämmrich, J. (2015). Gendered labor market outcomes at labor market entry and their relationship with country-specific characteristics: A comparative perspective. Gender, Education and Employment, Edward Elgar Publishing.

England, P. (2010). The Gender Revolution: Uneven and Stalled. Gender \& Society 24(2): 149-166.

Flashman, J. (2013). A cohort perspective on gender gaps in college attendance and completion. Research in Higher Education, 54(5), 545-570.

Göksel, İ. (2013,). Female labor force participation in Turkey: The role of conservatism. Women's Studies International Forum, 4, 45-54. 
Gündüz-Hoşgör, A., \& Smits, J. (2007). The status of rural women in Turkey: What is the role of regional differences. In V. Moghadam (Ed.), Empowering women: Participation, rights and women's movements in the Middle East, North Africa, and South Asia. Syracuse: Syracuse University Press.

Gündüz-Hoşgör, A., \& Smits, J. (2008). Variation in labor market participation of married women in Turkey. In Women's Studies International Forum, 31(2), 104-117.

Hakim, C (2001). Work-Lifestyle Choices in the 21st Century: Preference Theory. Oxford, Oxford University Press.

İlkkaracan, İ. (2012). Why so few women in the labor market in Turkey? Feminist Economics, 18(1), 1-37.

Marginson, S. (2016). The worldwide trend to high participation higher education: Dynamics of social stratification in inclusive systems. Higher Education, 72(4), 413-434.

Mizikaci, F. (2003). Quality systems and accredition in higher education: An overview of Turkish higher education. Quality in Higher Education, 9(1), 95-106.

MoNE (Ministry of National Education) (2019) National Education Statistics Formal Education 2018/2019. Ministry of National Education Strategy Development Presidency: Ankara

OECD. (2008). Higher education to 2030. Volume 1: Demography. Paris: OECD. Database.

OECD. (2018). Employment outlook. Paris: OECD.

Polat, S. (2017). The expansion of higher education in turkey: Access, equality and regional returns to education. Structural Change and Economic Dynamics, 43, 1-14.

Reimer, D., Noelke, C., \& Kucel, A. (2011). Labor market effects of field of study in comparative perspective: an analysis of 22 European countries. International Journal of Comparative Sociology, 49(4), 232-256.

Reimer, D. and S. Steinmetz (2009). Highly educated but in the wrong field? Educational specialisation and labour market risks of men and women in Spain and Germany. European Societies 11(5): 723746.

Schendel, R., \& McCowan, T. (2016). Expanding higher education systems in low- and middle income countries: The challenges of equity and quality. Higher Education, 72(4), 407-411.

Smits, J., \& Gündüz-Hoşgör, A. (2006). Effects of family background characteristics on educational participation in Turkey. International Journal of Educational Development, 26(5), 545-560.

Smyth, E., \& Steinmetz, S. (2008). Field of study and gender segregation in European labour markets. International Journal of Comparative Sociology, 49(4-5), 257-281.

Steinmetz, S. (2012). The contextual challenges of occupational sex segregation. Wiesbaden, Springer.

Tam, T. (1997). Sex Segregation and Occupational Gender Inequality in the United States: Devaluation or Specialized Training? American Journal of Sociology 102(6): 1652-1692.

TUIK (Türkiye Istatistik Kurumu) (2018) 2017 İşgücü Istatistikleri. Ankara.

World Bank. (2015). Supply and Demand for Child Care Services in Turkey: A Mixed Methods Study. Report no.: 98884-TR.

Yun, M.-S. (2004). Decomposing differences in the first moment. Economic Letters 82(2): 275-280. 